\title{
Article \\ First Principle Analysis on Pyridine Amide Derivatives' Adsorption Behavior on the Pt (111) Surface
}

\author{
Guocai Tian *, Huanhuan Du and Hongmei Zhang
}

check for

updates

Citation: Tian, G.; Du, H.; Zhang, H. First Principle Analysis on Pyridine Amide Derivatives' Adsorption Behavior on the $\mathrm{Pt}$ (111) Surface. Crystals 2021, 11, 98. https:// doi.org/10.3390/cryst11020098

Academic Editor: Paolo Restuccia Received: 28 December 2020

Accepted: 22 January 2021

Published: 24 January 2021

Publisher's Note: MDPI stays neutral with regard to jurisdictional claims in published maps and institutional affiliations.

Copyright: (c) 2021 by the authors. Licensee MDPI, Basel, Switzerland. This article is an open access article distributed under the terms and conditions of the Creative Commons Attribution (CC BY) license (https:// creativecommons.org/licenses/by/ $4.0 /)$.
Faculty of Metallurgical and Energy Engineering, State Key Laboratory of Complex Non-Ferrous Metal Resource Clean Utilization, Kunming University of Science and Technology, Kunming 650093, China; yunduoxiaoshan@163.com (H.D.); zhm65296@163.com (H.Z.)

* Correspondence: tiangc@kust.edu.cn; Tel.: +86-871-6519-8154

\begin{abstract}
The reactivity and adsorption behavior of three pyridine amide additives (Nicotinamide, Pyridine-2-formamide and Pyridine-4-formamide) on the Pt (111) surface was studied by First principle methods. The quantum chemical calculations of molecular reactivity show that the frontier orbitals of the three additives are distributed around the pyridine ring, oxygen atom of carbonyl and nitrogen atom of amino, and the nucleophilic and electrophilic active centers are located on the nitrogen atoms of pyridine ring, oxygen atom of carbonyl and nitrogen atom of amino. All three molecules were adsorbed with the chemical adsorption on the Pt (111) surface, and the order of adsorption was Nicotinamide $>$ Pyridine-2-formamide $>$ Pyridine-4-formamide. The $\mathrm{C}$ and $\mathrm{N}$ atoms of three derivatives forms C-Pt and N-Pt bonds with the Pt atoms of the Pt (111) surface, which makes derivatives stably adsorb on the Pt surface and form a protective film. The protective film inhibits the diffusion of atoms to the surface of the growth center, so as to inhibit the formation of dendrite and obtain a smooth aluminum deposition layer.
\end{abstract}

Keywords: adsorption behavior; pyridine amide additives; first principle; molecular reactivity; aluminum deposition; chemical adsorption; Pt surface

\section{Introduction}

Aluminum and aluminum alloys are commonly used in the fields of national defense industry, aviation industry, automobile manufacturing, electronics and daily necessities manufacturing with their excellent properties [1,2]. The commonly used method of industrial aluminum production is Hall-Héroult method, which has the problems of high energy consumption, serious corrosion of equipment, environmental pollution etc. [3,4]. It is urgent to seek a low-temperature green production method of aluminum, and it is also a research hotspot in this field. In recent years, significant progress has been made in low temperature aluminum electrolysis. The main work focuses on the replacement of cryolite molten salt system by molten salt system with lower melting point such as chloride or fluoride. These methods can reduce the electrolysis temperature to a certain extent, but the reduction is not enough [2-4]. The appearance of ionic liquids provides a possibility for the development of low-temperature aluminum electrolysis technology.

Ionic liquid is a kind of ionic system which is composed of some inorganic or organic anions and organic cations and is liquid at or near room temperature [5-8]. It has the advantages of non-volatile, wide electrochemical window, wide liquid temperature range, good thermal stability, conductivity and variable combination of properties, and is widely and successfully used in various fields such as electrochemistry (electrodeposition, battery), catalysis, organic synthesis, extraction and separation [5-16]. In recent years, ionic liquids, as a new type of green electrolyte, have been used for aluminum electrodeposition and electrolysis refining at or near room temperature, and some progress has been made [9-14]. However, there are still some problems to be solved, such as high electrolyte viscosity and 
dendrite phenomenon in the deposition layer [11-14]. The addition of additives is one of the common methods to address these problems $[15,16]$.

The effects of additives such as chloride, acetonitrile, aromatic compounds, carbonyl small molecules, haloalkanes, nicotinic acid and their derivatives on electrodeposition of aluminum in ionic liquids have been studied, and some progress has been made [17-30]. Leng et al. [24] studied the effect of methyl carbonate on electrodeposition of aluminum in $[\mathrm{EMIM}] \mathrm{Cl} / \mathrm{AlCl}_{3}$ system by cyclic voltammetry. Endres et al. $[27,28]$ found that Nano $\mathrm{Al}$ could be prepared by adding nicotinic acid into $[\mathrm{EMIM}] \mathrm{Cl} / \mathrm{AlCl}_{3}$. The effect of aromatic hydrocarbons on electrodeposited aluminum in $[\mathrm{Bmim}] \mathrm{Cl} / \mathrm{AlCl}_{3}$ was by cyclic voltammetry [29]. It was found that the morphology of Al coating became smoother, more uniform and denser with the increase of additive concentration. It was found that adding $45 \mathrm{mmol} / \mathrm{L}$ of methyl carbonate can significantly improve the brightness of $\mathrm{Al}$ and obtain a fine, uniform and bright $\mathrm{Al}$ deposition layer. It can be seen that additives can reduce dendrite and energy consumption in the process of aluminum electrolytic deposition, and change the size of the aluminum film from micron scale to nano-meter scale [14-30]. However, the current researches cannot reveal the detailed information of the mechanism of the additives, such as the bonding, electron transfer, interaction between the molecules and the metal surface, and their influence on the quality of the aluminum deposition layer are not clear.

In recent years, with the development of computational techniques and methods, First Principles method has become an effective means to study the structure, properties and reaction mechanism of compounds and materials. By calculating the frontier orbital distribution, Fukui index, charge distribution of heavy atoms and other quantum chemical parameters, people can study the reaction activity, charge transfer, structure-activity relationship and so on. The microscopic interaction and reaction mechanism between molecules can be deeply revealed from these quantum chemical parameters, which provide a useful way to understand adsorption behavior between molecules and interfaces at the atomic and molecular levels. At present, it has been successfully applied to the study of various metal surface properties [31-33]. Valencia et al. [31,32] studied the adsorption mechanism of [EMIM] $\mathrm{BF}_{4}$ on the $\mathrm{Li}(100)$ surface with density functional theory (DFT), and found that adding a small amount of [EMIM] $\mathrm{BF}_{4}$ to Li ion battery can prevent dendrite formation and improve battery performance. Clarke et al. [33] studied the effect of $\left[\mathrm{EtNH}_{3}\right] \mathrm{BF}_{4}$ on the Li-ion battery system by DFT and molecular dynamics simulation (MD). It is found that the Li-F bond between $\mathrm{BF}_{4}$ anion and lithium surface forms $\mathrm{Li}_{x} \mathrm{BF}_{4}$ clusters, which makes the interface between $\left[\mathrm{EtNH}_{3}\right] \mathrm{BF}_{4}$ and the electrode more stable and reduces the dendrite formation. These works provide a new way to explore the interaction mechanism between additives and metal surface in ionic liquids.

Aromatic compounds, as a kind of ring compounds with delocalized bonds, are widely used as additives in electrolysis and electroplating because of their stable structure and difficult decomposition. Pyridine derivatives have been widely used because of their strong polarization and leveling ability in solution and ionic liquids [9-12]. It is found that Nicotinamide, Pyridine-2-formamide and Pyridine-4-formamide can be used as effective leveling agents for electrodeposition of aluminum in $[\mathrm{Bmim}] \mathrm{Cl} / \mathrm{AlCl}_{3}$ [34]. The results showed that the order of the deposition was Nicotinamide $>$ Pyridine-2-formamide $>$ Pyridine-4-formamide. However, the mechanism is still unclear, especially the interaction between additives and electrode, charge transfer and adsorption behavior and characteristics. Due to its stable chemical properties (not easy to be oxidized, corroded, etc.) and low hydrogen evolution overpotential, platinum has very important applications in electrochemistry, such as auxiliary electrode, modified electrode substrate, electrocatalysis, etc. Platinum electrode is commonly used in the measurement of electrochemical properties of aqueous solution, molten salt, organic electrolyte and ionic liquid, such as cyclic voltammetry, polarization curve and electrochemical impedance. Therefore, it is very important to study the adsorption of molecules on the surface of Pt electrode. At the same time, platinum has good catalytic performance, which is used as a catalyst in fuel cell, 
petrochemical industry, automobile exhaust purification and other fields. In this paper, the interaction mechanism of Nicotinamide, Pyridine-2-formamide and Pyridine-4-formamide with Pt (111) surface was studied by First Principles method. The reactivity and adsorption behavior of the three additives on the Pt (111) surface were analyzed, and the interaction mechanism of Pyridine amide derivatives on the Pt surface was revealed, to provide a theoretical reference and guidance for additives' design to electrodeposition of aluminum in ionic liquids.

\section{Materials and Methods}

The stable configuration, global and local reactivity parameters of Nicotinamide, Pyridine-2-formamide and Pyridine-4-formamide were calculated by commonly used B3LYP hybrid density functional in the Gaussian 09 software package [35]. The structure was fully optimized, and the related properties were calculated at the $6-311++G(d, p)$ basis set. After optimization, the vibration frequency analysis was carried out to confirm the stable geometry without imaginary frequency. The results can be compared with the mp2 results. Then the physical quantity, frontier orbital distribution and Fukui index of the stable geometry are calculated and plotted by Multiwfn [36].

The Vienna ab initio simulation package (VASP) code has been used for the periodic surface adsorption calculations [37,38]. A cutoff energy of $400 \mathrm{eV}$ was used. The electron-ion interaction was described with the projector augmented wave (PAW) method. Exchange and correlation effects are treated in the generalized gradient approximation (GGA) in the formulation of PBE [39]. The most popular method of DFT-D3 with the BJ-damping method proposed by Stefan Grimme, was used to consider the VDW for present system [40]. The lattice parameters obtained by optimizing the Pt cell structure were consistent with the previous experimental value of $3.92 \AA$ [41]. A three-dimensional periodic structure is used to replace the infinite $\mathrm{Pt}$ surface. $\mathrm{Pt}$ (111) is selected as the research object because it is the most stable low Miller index surface of Pt surface, and used to study the absorption behavior of pyridine and other aromatic chemical compounds on Pt surface [41,42]. Four-layer-thick slabs (16 atoms in each layer) were used, and the additive molecule was chemisorption on the upper face only. A vacuum layer of $20 \AA$ is constructed on the upper layer of each cell to ensure that there is no interaction between periodic structures. In the geometry optimizations, the coordinates of the molecule and two uppermost metallic layers were relaxed. Brillouin-zone integrations have been performed using a $4 \times 4 \times 1$ Monkhorst-Pack grid and a Methfessel-Paxton smearing of $0.25 \mathrm{eV}$. The electron convergence criterion is set to $0.00001 \mathrm{eV}$ by default, and the ion relaxation is set to $0.050 \mathrm{eV} / \AA$. In the initial configuration, the additive molecule is placed on the $\mathrm{Pt}(111)$ in parallel with the previous study of imidazole system [42], and the adsorption energy $\left(E_{\mathrm{ad}}\right)$ is defined as follows,

$$
E_{\mathrm{ad}}=E_{\text {total }}-E_{\text {surface }}-E_{\text {molecule }}
$$

Among them, $E_{\mathrm{ad}}$ is adsorption energy of a molecule adsorbs on the $\mathrm{Pt}(111)$ surface, $E_{\text {total }}$ is the total energy of the system when the additive molecule adsorbs on the surface, and $E_{\text {surface }}$ and $E_{\text {molecule }}$ represent the total energy of the Pt surface without adsorbed molecule and the total energy of the additive molecule respectively. Depending on the above definition, $E_{\mathrm{ad}}$ of stable adsorption is negative. The density of states (DOS) and partial density of states (PDOS) was analyzed to obtain the electronic structure and properties of the relaxation structure before and after absorption.

\section{Results and Discussion}

\subsection{Molecular Frontier Orbital Distributions}

The frontier orbitals include the highest occupied orbitals (HOMO) and the lowest unoccupied orbitals (LUMO). The highest occupied orbit is the outermost orbit occupied by electrons in a molecule, which indicates the ability of the molecule to provide electrons. The lowest unoccupied orbital is the innermost orbital not occupied by electrons in a 
molecule, which shows the ability of a molecule to obtain electrons. Depending on the frontier orbital theory $[35,43]$, the interaction between reactants in a chemical reaction only occurs between the frontier orbitals of molecules, and HOMO and LUMO determine the reaction activity of molecules. Therefore, the frontier orbitals of molecules play a major role in the chemical reactions. The reactivity of molecules can be calculated by analyzing the distribution of HOMO and LUMO. Optimized stable geometry structures of three additives are shown in Figure 1. The HOMO and LUMO isosurface maps of these three molecules are illustrated in Figure 2. It can be seen from Figure 2 that HOMO of Nicotinamide and Pyridine-2-carboxamide is distributed on the pyridine ring except $\mathrm{C} 3$ atoms, and Pyridine4-carboxamide is distributed on the whole pyridine ring. They are also allocated on the $\mathrm{C}, \mathrm{N}$ and $\mathrm{O}$ atoms of substituents, and these atoms have electrophilic activity. For LUMO, Nicotinamide and Pyridine-2-carboxamide are distributed on the pyridine ring and $\mathrm{C}, \mathrm{N}$ and $\mathrm{O}$ atoms of substituents, while Pyridine-2-carboxamide is distributed on the pyridine ring and $\mathrm{C}, \mathrm{N}$ and $\mathrm{O}$ atoms of substituents except $\mathrm{C} 13$ atom. The HOMO and LUMO of the three molecules are delocalized on the pyridine ring, $\mathrm{N}$ atoms of amino and $\mathrm{O}$ atoms of carbonyl. It indicates that the pyridine rings, $\mathrm{N}$ atoms of amino and $\mathrm{O}$ atoms of carbonyl are the active regions of the molecules. Due to the atoms in the pyridine ring, $\mathrm{N}$ atoms and O oxygen of the three derivative molecules are basically coplanar, and it is easy to form conjugated large $\pi$ bonds, which enhances the overall activity of the three molecules and makes the molecules parallel to the surface in a flat way. In addition, HOMO and LUMO cover almost all the heavy atoms in the molecule.

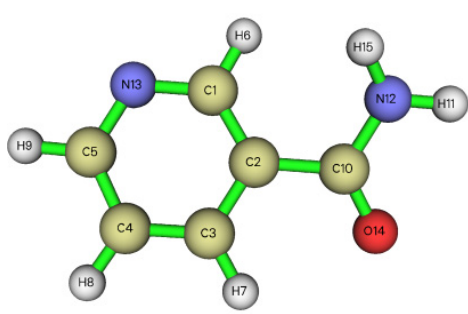

(a) Nicotinamide

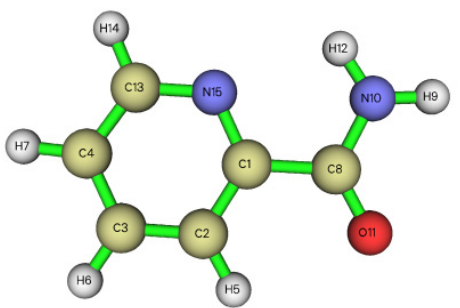

(b) Pyridine-2-carboxamide

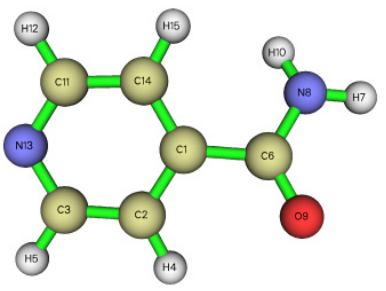

(c) Pyridine-4-carboxamide

Figure 1. Optimized structures of three molecules (a) Nicotinamide, (b) Pyridine-2-carboxamide, (c) Pyridine-4-carboxamide at B3LYP/6-311++G $(d, p)$ level.

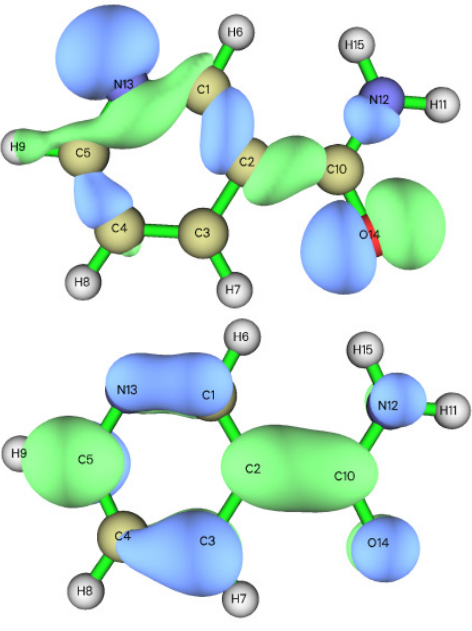

(a) Nicotinamide
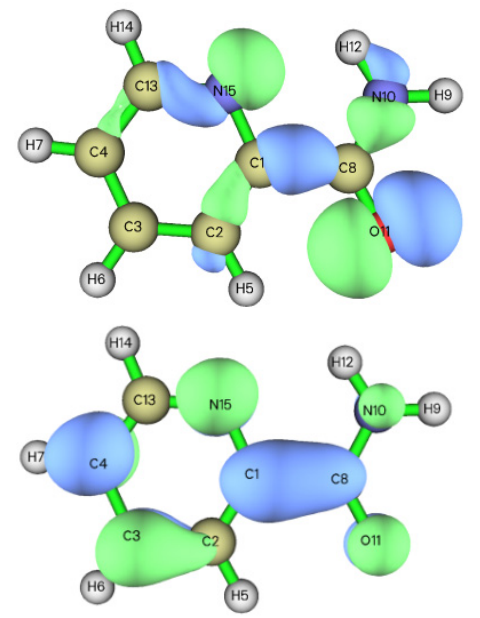

(b) Pyridine-2-carboxamide
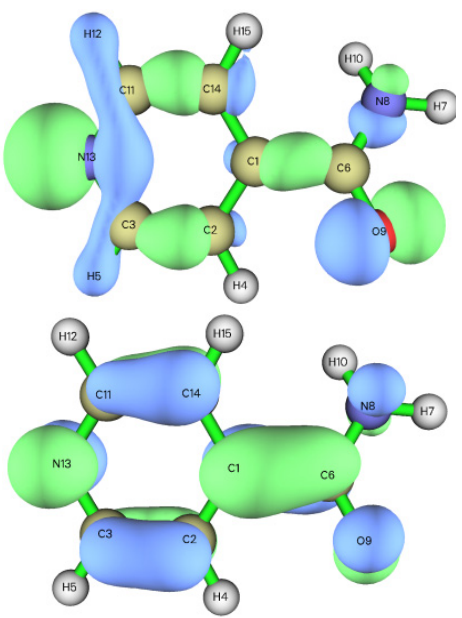

(c) Pyridine-4-carboxamide

Figure 2. Frontier orbital isosurface with value of 0.03 a.u. calculated with B3LYP/6-311++G (d, p) for three additive molecules (top, the highest occupied orbitals HOMO; bottom, the lowest unoccupied orbitals LUMO) (a) Nicotinamide, (b) Pyridine-2-carboxamide, (c) Pyridine-4-carboxamide. 


\subsection{Molecular Local Reactivity}

\subsubsection{Charge Distribution}

Through the analysis of the molecular frontier orbitals of the three additives, the active regions of the molecules were obtained. Taking into account the charge distribution and Fukui index of each atom in the molecules, the local reactivity of the molecules was also analyzed [44]. The Mulliken charge distributions of atoms in the three derivatives are listed in Table 1. It can be seen from Table 1 that C1, C5, C10, N12 and O14 atoms in Nicotinamide molecule have more negative charges, which are consistent with the contribution of HOMO in Figure 1a. It can be concluded that these atoms are electrophilic active centers of Nicotinamide molecule. C4 and N13 with a small amount of negative charge have a certain electrophilic activity. At the same time, these atoms contribute a lot to LUMO, which indicates that these atoms also have some nucleophilic activity. C3, N10 and $\mathrm{O} 11$ atoms in Pyridine-2-carboxamide molecule have more negative charges, which are consistent with the contribution of HOMO in Figure $1 \mathrm{~b}$. It can be concluded that these atoms are electrophilic active centers of Pyridine-4-carboxamide molecule. C1, C8, C13 and N15 atoms have a small amount of negative charge and have a certain electrophilic activity. At the same time, these atoms contribute a lot to LUMO, which indicates that these atoms also have some nucleophilic activity. C3, C11, N8, O9 and C6 atoms in Pyridine4-carboxamide have more negative charges, which is consistent with the contribution of HOMO in Figure 1c. It can conclude that these atoms are electrophilic active centers of Pyridine-4-carboxamide. N13 with a small amount of negative charge has a certain electrophilic activity. At the same time, these atoms contribute a lot to LUMO, which indicates that these atoms also have some nucleophilic activity.

Table 1. Mulliken charges for three additive molecules.

\begin{tabular}{cccccc}
\hline \multicolumn{2}{c}{ Nicotinamide } & \multicolumn{2}{c}{ Pyridine-2-Carboxamide } & \multicolumn{2}{c}{ Pyridine-4-Carboxamide } \\
\hline Atoms & Charge & Atoms & Charge & Atoms & Charge \\
\hline C1 & -0.66 & C1 & -0.20 & C1 & 0.49 \\
C2 & 0.81 & C2 & 0.48 & C2 & 0.24 \\
C3 & 0.04 & C3 & -0.69 & C3 & -0.53 \\
C4 & -0.10 & C4 & 0.14 & H4 & 0.22 \\
C5 & -0.35 & H5 & 0.25 & H5 & 0.18 \\
H6 & 0.17 & H6 & 0.18 & C6 & -0.29 \\
H7 & 0.22 & H7 & 0.19 & H7 & 0.32 \\
H8 & 0.19 & C8 & -0.12 & N8 & -0.35 \\
H9 & 0.19 & H9 & 0.32 & O9 & -0.32 \\
C10 & -0.33 & N10 & -0.40 & H10 & 0.23 \\
H11 & 0.31 & O11 & -0.38 & C11 & -0.55 \\
N12 & -0.35 & H12 & 0.28 & H12 & 0.17 \\
N13 & -0.03 & C13 & -0.23 & N13 & -0.04 \\
O14 & -0.33 & H14 & 0.19 & C14 & 0.06 \\
H15 & 0.23 & N15 & -0.02 & H15 & 0.17 \\
\hline
\end{tabular}

\subsubsection{Fukui Index Analysis}

Fukui index can accurately reflect the activity of each atom in the additive molecule, and can locate the nucleophilic or electrophilic reaction center of the molecule, which is an effective method to determine the molecular reaction center and its strength [43]. $f^{+}{ }_{i}(r)$ and $f^{-}{ }_{i}(r)$ denote the nucleophilic Fukui index and the electrophilic Fukui index respectively, indicating the strength of the ability of an atom $i$ to accept or donate electrons. The larger the value is, the stronger the ability to accept or donate electrons is [44]. The $f^{+}{ }_{i}(r)$ and $f^{-}{ }_{i}(r)$ of all atoms in the three additives are provided in Figure 3. It can be seen from Figure 3 that $f^{+}{ }_{i}(r)$ values of $\mathrm{C} 5, \mathrm{O} 14, \mathrm{C} 10, \mathrm{C} 2, \mathrm{C} 3$ and N12 atoms in Nicotinamide are larger, indicating that these atoms have nucleophilic activity. The $f^{-}{ }_{i}(r)$ values of O14, N15, N12 and C2 atoms are bigger, indicating that these atoms have electrophilic activity. O14, N12 and C2 atoms are electrophilic active centers and nucleophilic active centers, so O14, N12 and C2 
atoms should be preferentially adsorbed on the $\operatorname{Pt}(111)$ surface. The larger $f^{+}{ }_{i}(r)$ values of $\mathrm{O} 11, \mathrm{C} 1, \mathrm{~N} 15, \mathrm{C} 4, \mathrm{C} 3$ and N10 atoms in Pyridine-2-carboxamide indicate that these atoms have nucleophilic activity. The $f^{-}{ }_{i}(r)$ values of $\mathrm{O} 11, \mathrm{~N} 15, \mathrm{C} 1, \mathrm{~N} 10$ and $\mathrm{C} 13$ atoms are larger, indicating that these atoms have electrophilic activities. O11, N15, C1 and N10 atoms are both electrophilic active centers and nucleophile active centers, so O11, N15, C1 and N10 atoms should be preferentially adsorbed on the $\mathrm{Pt}(111)$ surface. The larger $f^{+}{ }_{i}(r)$ values of O9, C1, N13, C6 and N8 atoms in Pyridine-4-carboxamide indicate that these atoms have nucleophile activity. The $f^{-}{ }_{i}(r)$ values of $\mathrm{O} 9, \mathrm{~N} 8, \mathrm{~N} 13, \mathrm{C} 1, \mathrm{C} 11$ and $\mathrm{C} 14$ atoms are larger, indicating that these atoms have electrophilic activities. O9, N8, N13, C1, C11 and C14 atoms are both electrophilic and nucleophile active centers, so O9, N8, N13 and C1 atoms should be preferentially adsorbed on the $\mathrm{Pt}(111)$ surface. The results are in agreement with Section 3.2.1.

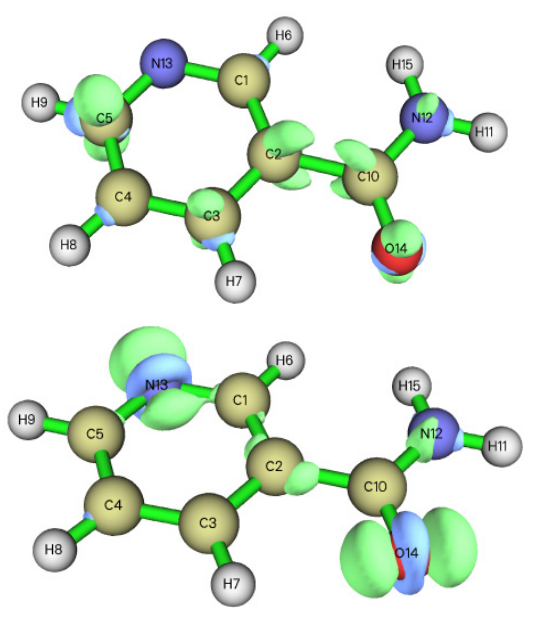

(a) Nicotinamide
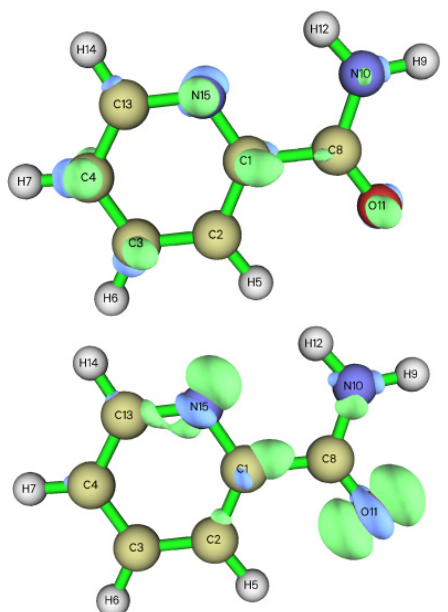

(b) Pyridine-2-carboxamide

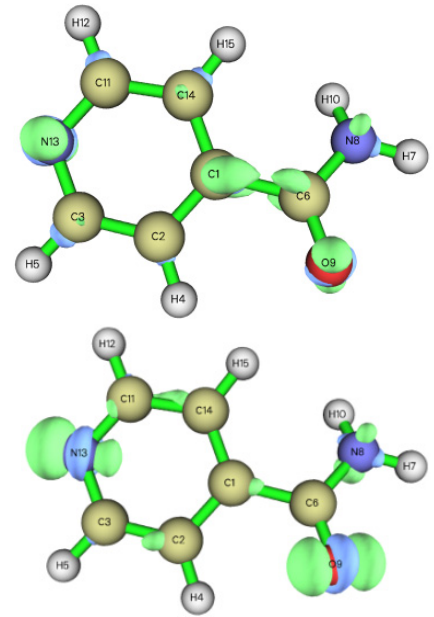

(c) Pyridine-4-carboxamide

Figure 3. Fukui functions with value of 0.01 a.u. for three additive molecules (top, $f^{+}(r)$; bottom, $\left.f^{-}(r)\right)$ (a) Nicotinamide, (b) Pyridine-2-carboxamide, (c) Pyridine-4-carboxamide.

\subsection{Adsorption of Three Derivative Molecules on the Pt (111) Surface}

According to previous studies and literature [41,42], the bridge adsorption site is the most stable adsorption site for pyridine molecules on the Pt surface. Therefore, we consider that three molecules are adsorbed in the bridge adsorption site on the $\mathrm{Pt}(111)$ surface in a parallel manner. Figure 4 shows the top view $(\mathrm{a}-\mathrm{c})$ and side view $(\mathrm{d}-\mathrm{f})$ of the optimized structure of Nicotinamide, Pyridine-2-formamide and Pyridine-4-formyl adsorbed on the $\mathrm{Pt}$ (111) surface, respectively. In the initial structure, the carbon rings are parallel to the surface at an average distance of about $2.1 \AA$. After optimization, the average distance between the carbon ring and the metal surface is about $2.2 \AA$. As can be seen from Figure $4 \mathrm{~d}-\mathrm{f}$, after optimization, it is found that the length of the $\mathrm{C}-\mathrm{C}$ bond in the ring group is extended, while the $\mathrm{C}-\mathrm{H}$ bond is bent upward, indicating that the hybrid state of carbon changes from planar type to non-planar type, thus forming a strong chemisorption bond.

It can be seen from Figure 4 that the three additives are adsorbed on the Pt surface in a horizontal form, and the $\mathrm{N}$ atom of the amino and one $\mathrm{Pt}$ atom forms the $\mathrm{N}-\mathrm{Pt}$ bond. However, there are some differences in the type and quantity of the bond between the pyridine ring and the Pt surface in the three additives. Figure 4a shows the stable configuration of Nicotinamide adsorbed on the Pt (111) surface. Each C atom in the pyridine ring is bonded with $\mathrm{Pt}$ surface atom, and the $\mathrm{Pt}$ atom is stretched upward to form two $\pi$ bonds and two $\sigma$ bonds. C2-C3 and C4-C6 form $\pi$-bonds with one Pt atom respectively. $\mathrm{C} 1$ atom forms an $\sigma$-bond with a $\mathrm{Pt}$ atom, and $\mathrm{N} 1$ atom forms an $\mathrm{N}-\mathrm{Pt}$ bond with a Pt atom. Figure $4 \mathrm{~b}$ shows the stable configuration of Pyridine-2-formamide adsorbed on the $\mathrm{Pt}$ (111) surface. Each $\mathrm{C}$ atom on the ring group is bonded with Pt surface, forming 
one $\pi$-bond and three $\sigma$-bonds. The $\mathrm{N}$ atom of the ring is not bonded with $\mathrm{Pt}$ atom. C3-C5 forms a $\pi$-bond with a $\mathrm{Pt}$ atom. C1, C2, and C6 atoms form $\sigma$-bonds with one Pt atom, respectively. Figure $4 \mathrm{c}$ shows the stable configuration of Pyridine-4-formyl adsorbed on the $\mathrm{Pt}$ (111) surface. Each $\mathrm{C}$ atom on the ring group forms adsorption bonds with $\mathrm{Pt}$ surface, forming two $\pi$-bonds and two $\sigma$-bonds. C2-C3 is a $\pi$-bond formed by two $\mathrm{C}$ atoms and one $\mathrm{Pt}$ atom, N1-C6 is a $\pi$-bond formed by two Pt atoms and one Pt atom. C1 and C4 atoms form $\sigma$-bonds with one $\mathrm{Pt}$ atom respectively.
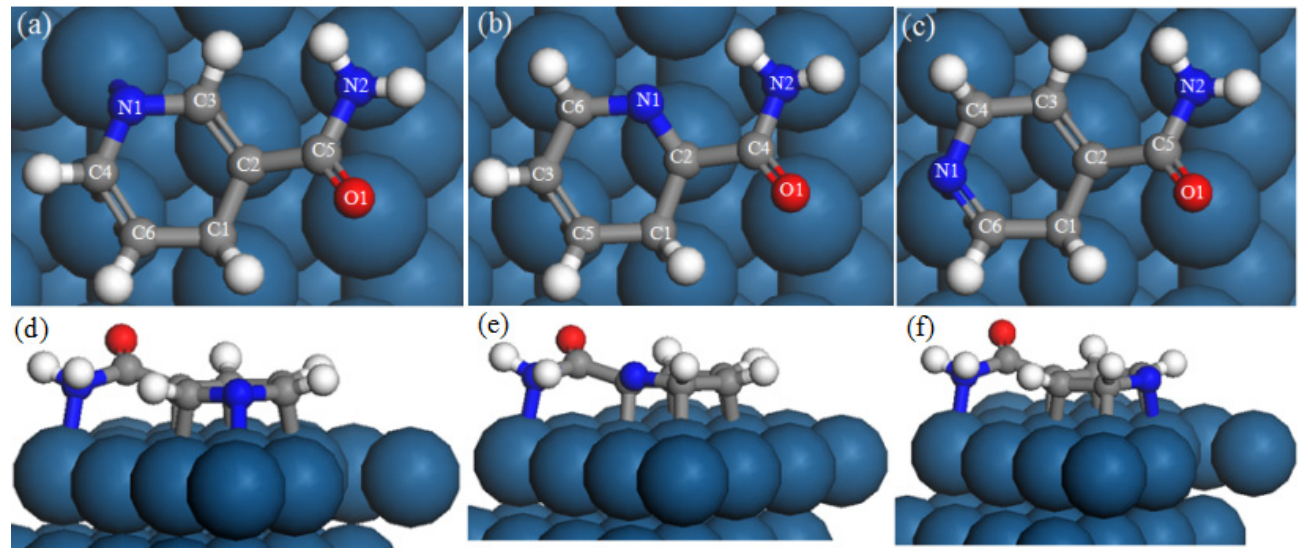

Figure 4. Top and side views of the most preferred adsorption configuration of Nicotinamide (a,d), Pyridine-2-carboxamide (b,e) and Pyridine-4-carboxamide (c,f) on the Pt (111).

Table 2 displays the calculated adsorption energy of the additive on the $\mathrm{Pt}(111)$ and the distance between the corresponding atoms after adsorption. It can be seen from Table 2 that the adsorption energy varies with the substituent position on the pyridine ring. The absolute value of the adsorption energy of meta-substituted Nicotinamide is the largest, which is $-2.04 \mathrm{eV}$, indicating that it has the strongest interaction with $\mathrm{Pt}$ (111). The C and $\mathrm{N}$ atoms of Nicotinamide are bonded to the nearest $\mathrm{Pt}$ atom. C-Pt bond growth is about $2.2 \AA$, and two N-Pt bond lengths are $2.16 \AA$ and $2.22 \AA$, respectively, which close to the experimental value of $2.09 \AA$. The adsorption energy of ortho-substituted Pyridine-2-carboxamide is $-1.79 \mathrm{eV}$. The $\mathrm{C}$ and $\mathrm{N}$ atoms of the Pyridine-2-carboxamide form adsorption bonds with the nearest $\mathrm{Pt}$ atom. Two $\mathrm{C}$ atoms are adsorbed on one $\mathrm{Pt}$ atom, and the C-Pt bond growth is about 2.2 $\AA$. The $\mathrm{N}$ atom of the substituent group is bonded with $\mathrm{Pt}$ atom, and the bond length is $2.23 \AA$. The adsorption energy of parasubstituted Pyridine-4-carboxamide is $-1.78 \mathrm{eV}$, and its adsorption bonding is similar to that of Nicotinamide, except that the $\mathrm{N}$ atom of the ring group and the adjacent $\mathrm{C}$ atom are adsorbed on a $\mathrm{Pt}$ atom. The adsorption of three additives on the $\mathrm{Pt}(111)$ surface is chemical adsorption [38]. The adsorption order of the three additives was Nicotinamide $>$ Pyridine-2-carboxamide $>$ Pyridine-4-carboxamide.

Table 2. Adsorption energy (eV) and structural parameters $(\AA)$ of three additives on the Pt (111).

\begin{tabular}{|c|c|c|c|c|c|c|c|c|c|}
\hline Additive & $E_{\mathrm{ad}}$ & $d_{\mathrm{N} 2-\mathrm{Pt}}$ & $d_{\mathrm{N} 1-\mathrm{Pt}}$ & $d_{\mathrm{C} 1-\mathrm{Pt}}$ & $d_{\mathrm{C} 2-\mathrm{Pt}}$ & $d_{\mathrm{C} 3-\mathrm{Pt}}$ & $d_{\mathrm{C} 4-\mathrm{Pt}}$ & $d_{\mathrm{C} 5-\mathrm{Pt}}$ & $d_{\mathrm{C} 6-\mathrm{Pt}}$ \\
\hline Nicotinamide & -2.04 & 2.22 & 2.16 & 2.17 & 2.17 & 2.25 & 2.20 & - & 2.23 \\
\hline Pyridine-2-carboxamide & -1.79 & 2.23 & - & 2.18 & 2.20 & 2.20 & - & 2.20 & 2.21 \\
\hline Pyridine-4-carboxamide & -1.78 & 2.21 & 2.22 & 2.17 & 2.16 & 2.22 & 2.14 & - & 2.25 \\
\hline
\end{tabular}

Three pyridine derivatives are adsorbed on the $\mathrm{Pt}$ (111) surface by chemisorption. They are strongly adsorbed on the Pt (111) surface to form a compact organic adsorption layer, which has a certain blocking effect on the passage of electric current, hinders the reduction of metal ions, significantly reduces the discharge rate of coordination ions, increases the overvoltage of electrode reaction, and slows down the electrode reaction rate, 
so that the electric current is reduced As a result, the growth rate at different positions on the surface tends to be the same, which prevents the appearance of coarse-grained and dendritic coatings formed by unidirectional growth. It can significantly change the quality of cathodic electro-deposition and obtain a flat and smooth deposition layer. Nicotinamide has the strongest adsorption, so it has the best leveling effect, which is consistent with the experimental observation.

\subsection{Electronic Structure Analysis}

In order to further analyze the adsorption mechanism of three pyridine derivatives on the $\mathrm{Pt}$ (111), the density of states (DOS) and partial density of the states (PDOS) diagrams before and after adsorption was calculated and shown in Figures 5-7. It can be seen from Figures $5-7$ that the contribution of the d electron of the atom on the $\mathrm{Pt}(111)$ plane to the total density of states is the largest, followed by the $\mathrm{s}$ and $\mathrm{p}$ orbital, but the contribution is relatively small. The p orbital electron of the additive molecule atom has the greatest contribution to the total density of states.

DOS of Nicotinamide/Pt (111) is shown in Figure 5a, and PDOS is shown in Figure 5b-d. After adsorption of Nicotinamide, the total DOS of Pt (111) changed to a certain extent, which showed that DOS increased in the range of $-7 \mathrm{eV}$ to $-9 \mathrm{eV}$. Depending on the PDOS of characteristic atoms in Figure $5 b-d$, the increase of DOS is mainly composed of $2 p$ orbitals of $\mathrm{C}$ and $\mathrm{N}$ atoms and $4 \mathrm{~s}$ and $3 \mathrm{~d}$ orbitals of $\mathrm{Pt}$ atoms. In Figure $5 \mathrm{~b}$, the $4 \mathrm{~s}$ orbital of $\mathrm{Pt}$ and the $2 \mathrm{p}$ orbital of $\mathrm{C}$ obviously overlap at $-6 \mathrm{eV}$, and the $3 \mathrm{~d}$ orbital of $\mathrm{Pt}$ and the $2 \mathrm{p}$ orbital of $\mathrm{C}$ obviously overlap at $-7 \mathrm{eV}$. The results show that the interaction between two atoms is the strongest, and the $\pi$-bond formed by $\mathrm{C}-\mathrm{C}$ atoms bonding to a Pt atom plays a major role in the adsorption process. In the adsorption structure, the $3 \mathrm{~d}$ and $4 \mathrm{~s}$ orbitals of $\mathrm{Pt}$ and the $2 \mathrm{p}$ orbitals of $\mathrm{C}$ are relatively active, and the hybridization between these orbitals occurs in the interaction process. In Figure $5 c$, there is a slight overlap between the $3 \mathrm{~d}$ orbital of the $\mathrm{Pt}$ atom and the $2 \mathrm{p}$ orbital of the $\mathrm{N}$ atom near $-7.2 \mathrm{eV}$. Therefore, it shows a weak interaction between $\mathrm{Pt}$ and $\mathrm{N}$ atoms. The results show that the $\mathrm{C}$ atom and $\mathrm{N}$ atom bond to one $\mathrm{Pt}$ atom to form $\sigma$-bond, which plays a secondary role in the adsorption process.
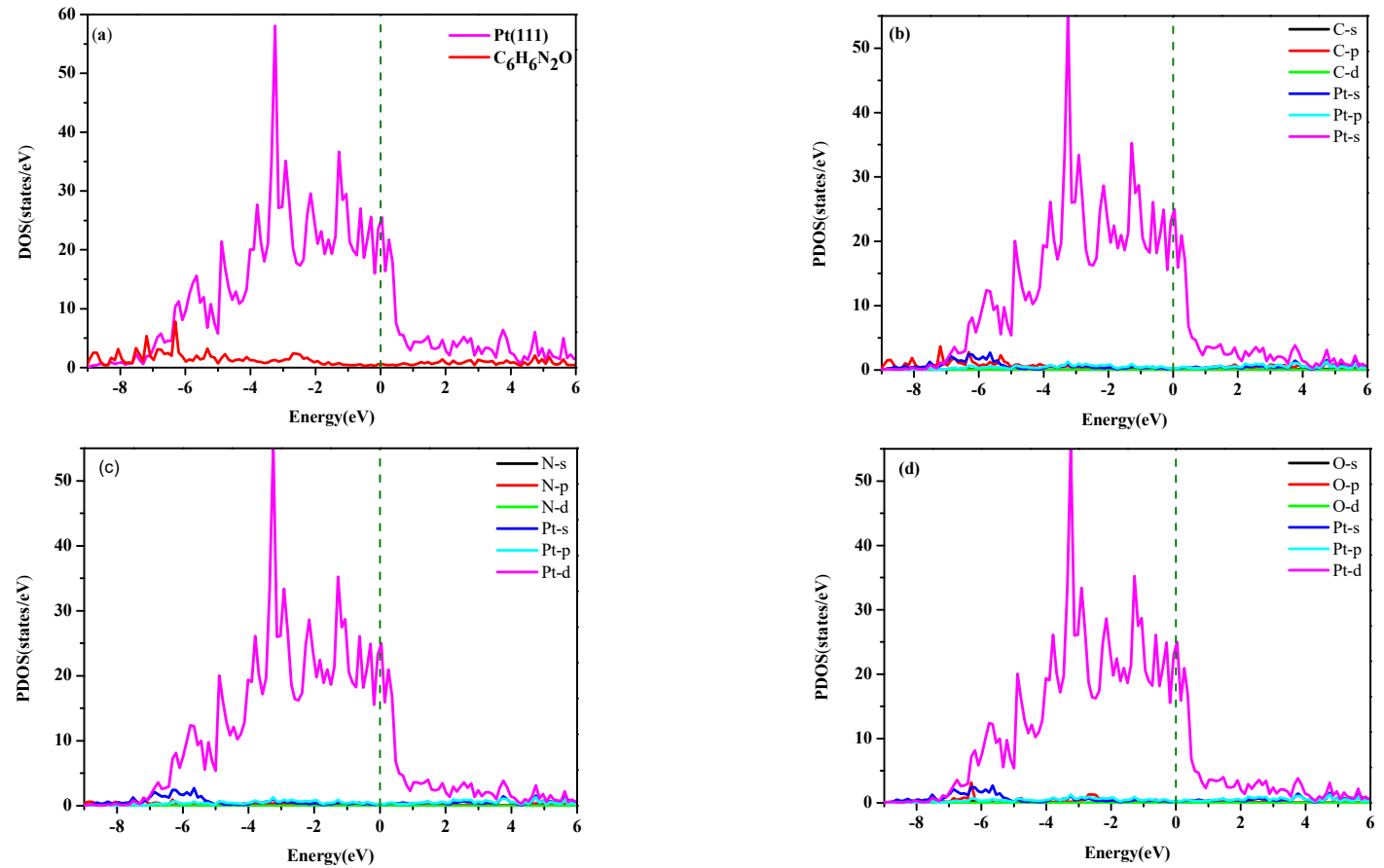

Figure 5. Densities of states (DOS) for Pt (111) with Nicotinamide absorption and partial Densities of states (PDOS) for major atom in the structure of Nicotinamide absorbed on the Pt (111). (a)Total DOS, (b) PDOS for C and Pt atoms, (c) PDOS for $\mathrm{N}$ and Pt atoms, (d) PDOS for $\mathrm{O}$ and Pt atoms. 

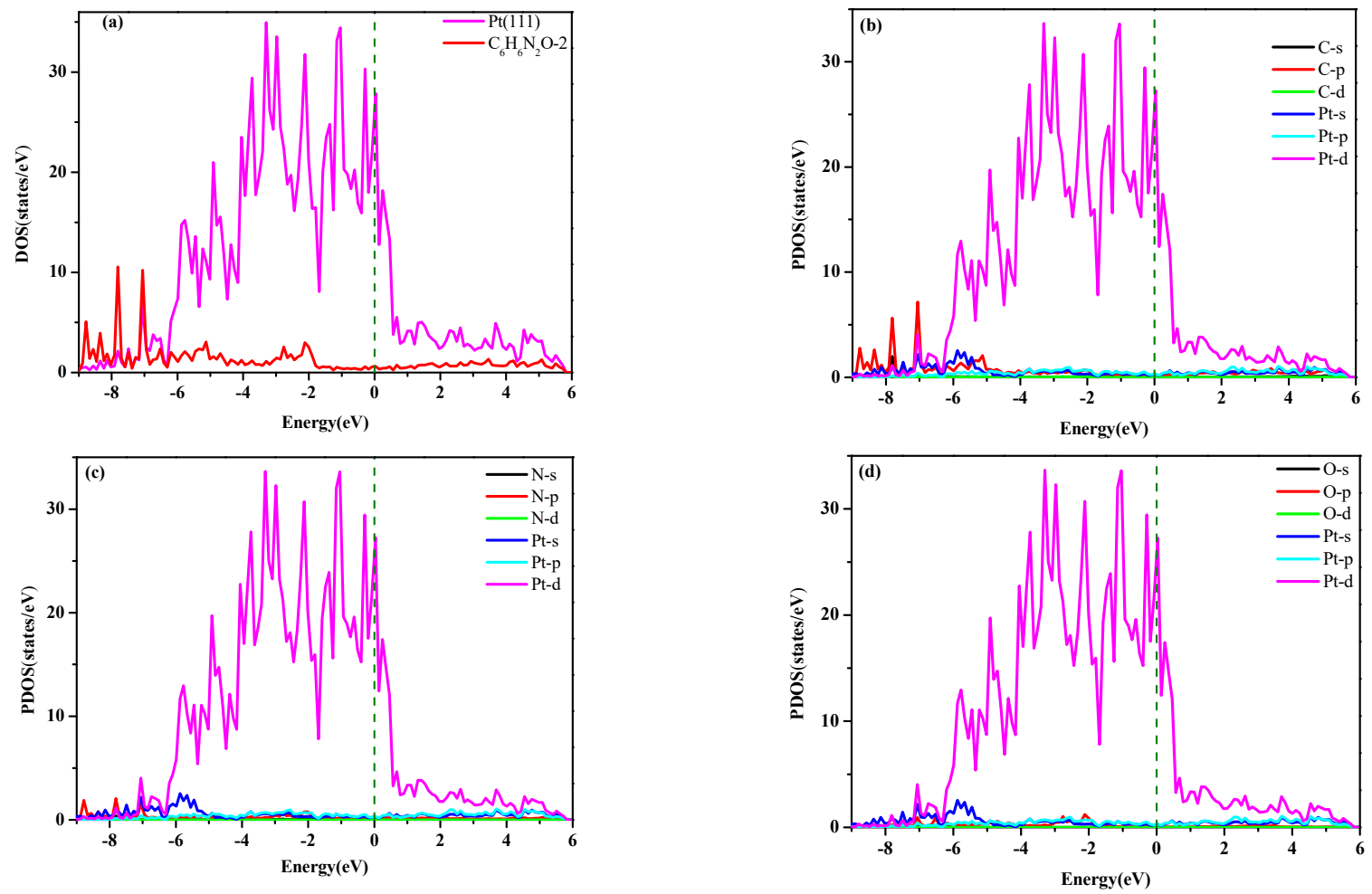

Figure 6. Densities of states (DOS) for Pt (111) with molecular absorption and partial Densities of states (PDOS) for major atom in the structure of Pyridine-2-carboxamide absorbed on the Pt (111). (a)Total DOS, (b) PDOS for C and Pt atoms, (c) PDOS for $\mathrm{N}$ and $\mathrm{Pt}$ atoms, (d) PDOS for $\mathrm{O}$ and Pt atoms.
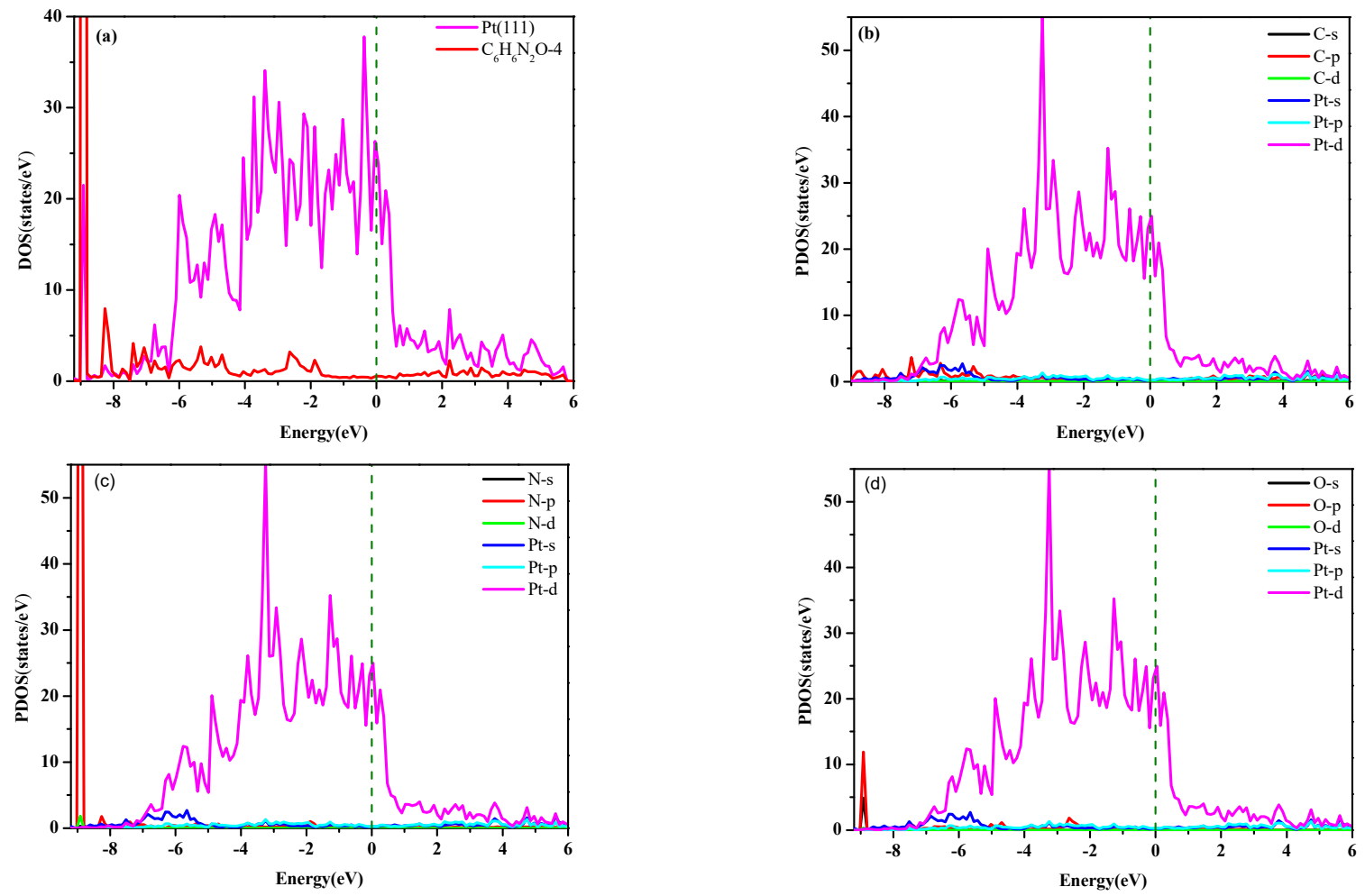

Figure 7. Densities of states (DOS) for Pt (111) with molecular absorption and partial Densities of states (PDOS) for major atom in the structure of Pyridine-4-carboxamide absorbed on the Pt (111). (a) Total DOS, (b) PDOS for C and Pt atoms, (c) PDOS for $\mathrm{N}$ and Pt atoms, (d) PDOS for $\mathrm{O}$ and Pt atoms. 
DOS of adsorbed Pyridine-2-carboxamide/Pt (111) is shown in Figure 6a, and PDOS is shown in Figure 6b-d. After adsorption, the total DOS of Pt (111) increased from $-9 \mathrm{eV}$ to $-6.9 \mathrm{eV}$, similar to that of Nicotinamide. The change of PDOS of the $\mathrm{C}$ atom is similar to that of Nicotinamide system. There is a slight overlap between the $3 \mathrm{~d}$ and $4 \mathrm{~s}$ orbitals of $\mathrm{Pt}$ atom and the $2 \mathrm{p}$ orbitals of the $\mathrm{N}$ atom of amino at $-8.3 \mathrm{eV}$ to $-7 \mathrm{eV}$. Due to the $\mathrm{N}$ atom of the ring not bonding with $\mathrm{Pt}$ atom, the $\pi$-bond formed by two $\mathrm{C}-\mathrm{C}$ atoms and one $\mathrm{Pt}$ atom plays the main role in the adsorption process of Pyridine-2-carboxamide system, and the interaction between $\mathrm{N}$ atom of amino and $\mathrm{Pt}$ atom plays the secondary role.

DOS of Pyridine-4-carboxamide/Pt (111) is shown in Figure 7a, and PDOS is shown in Figure 7b-d. The total DOS of $\mathrm{Pt}$ (111) increased in the range of $-9 \mathrm{eV}$ to $-7 \mathrm{eV}$ after Pyridine-4-carboxamide adsorption. In Figure $7 \mathrm{a}$, the $3 \mathrm{~d}, 4 \mathrm{~s}$ and $2 \mathrm{p}$ orbitals of $\mathrm{Pt}$ and $\mathrm{C}$ overlap at $-7.5 \mathrm{eV}$, and the $4 \mathrm{~s}$ and $2 \mathrm{p}$ orbitals of $\mathrm{Pt}$ and $\mathrm{C}$ overlap at $-6.3 \mathrm{eV}$. In Figure $7 \mathrm{c}$, the peak value of $2 \mathrm{p}$ orbital $-7 \mathrm{eV}$ of the $\mathrm{N}$ atom is the largest, which indicates that the interaction between the $\mathrm{N}$ atom and the metal surface is the largest. In this adsorption structure, the p orbital of N1-C6 on the ring forms $\pi$ bond with the d orbital of the Pt atom, and the $\mathrm{C}$ atom forms $\sigma$ bond with one Pt atom, which plays a secondary role.

Therefore, the $\pi$-bond between $\mathrm{C}$ and $\mathrm{N}$ atoms and $\mathrm{Pt}$ atom plays the main role, the $\sigma$-bond between $\mathrm{C}$ and $\mathrm{N}$ atoms and $\mathrm{Pt}$ atom plays the secondary role, and finally, the $\mathrm{N}$ atom of formamide substituent plays the role. Moreover, due to the substituents at different positions of the three additives, the bonding orbitals are different, which indicates that the interaction between the additives and $\mathrm{Pt}$ atoms is mainly caused by the hybridization of $2 \mathrm{p}$ orbitals of $\mathrm{C}$ and $\mathrm{N}$ atoms, and $4 \mathrm{~s}$ and $3 \mathrm{~d}$ orbitals of $\mathrm{Pt}$ atoms, forming a very stable internal orbital complex. It is very difficult for the ligands to separate from these complexes and form the activated complexes for the electrode reduction reaction. Therefore, the activation energy of cathodic reduction is very high and the rate of electrode reaction is very slow. This is why the additive molecules can form stable complexes with Pt and adsorb on the surface of Pt.

According to the above analysis, the additive has high surface activity and is strongly adsorbed on the metal surface. One or two $\mathrm{Pt}$ atoms are greatly attracted by the additive molecules, which is stabilized by the formation of C-Pt and $\mathrm{N}-\mathrm{Pt}$ bonds between $\mathrm{C}, \mathrm{N}$ atoms and $\mathrm{Pt}$ (111) surface, resulting in the electron transfer of the attracted $\mathrm{Pt}$ atoms to the additive molecules, and part of the electrons are also obtained on the metal surface. As a result, the additive molecules are strongly adsorbed on the Pt surface to form a film. With the increase of cathode current density, the additive may be preferentially adsorbed on the high current density part of the electrode, which may reduce the reaction speed of electrodeposition of metal ions, makes the precipitated grains finer, and makes the current distribution at the low current density part of the electrode tend to be uniform, thus inhibiting the formation of dendrites, resulting in a smooth aluminum deposition layer.

\section{Conclusions}

The reactivity and adsorption behavior of three pyridine amide derivatives' additives (Nicotinamide, Pyridine-2-formamide and Pyridine-4-formamide) on the Pt (111) surface was studied and analyzed by density functional theory. The frontier orbitals of the three additives are distributed on the pyridine ring, carbonyl $\mathrm{O}$ and amino $\mathrm{N}$ atoms, and the nucleophilic and electrophilic active centers are located on the $\mathrm{N}$ atoms of the pyridine ring, carbonyl $\mathrm{O}$ and amino $\mathrm{N}$ atoms. Three pyridine amide derivatives are adsorbed on the surface of $\mathrm{Pt}$ (111) with chemisorption, and the adsorption order was Nicotinamide > Pyridine-2-formamide $>$ Pyridine-4-formamide. It is in agreement with the experimental observation that Nicotinamide is the best leveling additive. The different substituent positions on the Pyridine ring affect the type and number of the adsorption bonds between $\mathrm{C}, \mathrm{N}$ atoms of the ring and Pt atoms. The $\pi$-bond formed by the bond between $\mathrm{C}, \mathrm{N}$ atoms and $\mathrm{Pt}$ atoms on the ring has the greatest influence on the molecular structure and adsorption performance, followed by the $\sigma$-bond formed by the bond with Pt atoms, and finally, the $\pi$-bond formed by the bond between $\mathrm{C}, \mathrm{N}$ atoms and $\mathrm{Pt}$ atoms. The formation of 
C-Pt and N-Pt bonds between $\mathrm{C}$ and $\mathrm{N}$ atoms and the Pt surface enhanced the absorption of additives on the Pt surface to form a film which inhibits the diffusion of atoms to the surface of the growth center, so as to inhibit the formation of dendrites and obtain a smooth aluminum deposition layer.

Author Contributions: Conceptualization, methodology, investigation, and writing of the original draft preparation were done by G.T., whereas the partial computational work of absorption was done by H.D. and H.Z. All authors have read and agreed to the published version of the manuscript.

Funding: This research was funded by National Natural Science Foundation of China (grant numbers 51774158, 5126402) and Cultivating Plan Program for the Leader in Science and Technology of Yunnan Province (grant number 2011HR013).

Institutional Review Board Statement: Not applicable.

Informed Consent Statement: Not applicable.

Data Availability Statement: Data is contained within the article.

Acknowledgments: The authors wish to thank the National Natural Science Foundation of China and the Department of Science and Technology of Yunnan Province for their support on the project no. 51774158, 5126402, and the project no. 2011HR013.

Conflicts of Interest: The authors declare no conflict of interest. The funders had no role in the design of the study; in the collection, analyses, or interpretation of data; in the writing of the manuscript, or in the decision to publish the results.

\section{References}

1. Wei, C. Electrochemical deposition of aluminum. Technol. Innov. Appl. 2019, 18, 80-81.

2. Liu, Y.X.; Li, J. Modern Aluminum Electrolysis; Metallurgical Industry Press: Beijing, China, 2008.

3. Yang, H.M.; Qiu, Z.X.; Zhang, G. Low Temperature Aluminum Electrolysis; Northeast University Press: Shenyang, China, 2009.

4. Lu, H.M.; Qiu, Z.X. Research progress of low temperature aluminum electrolysis. Light Metals 1997, 4, 24.

5. Deng, Y.Q. Ionic Liquids_Properties, Preparation and Application; China Petrochemical Press: Beijing, China, 2006.

6. Zhang, S.J.; Lu, X.M. Ionic Liquids, from Basic Research to Industrial Application; Science Press: Beijing, China, 2006.

7. Wasserscheid, P.; Welton, T. Ionic Liquids in Synthesis; John Wiley \& Sons: Hoboken, NJ, USA, 2008.

8. Zhang, M.; Kamavarum, V.; Reddy, R.G. New electrolytes for aluminum production, Ionic liquids. JOM 2003, 55, 54. [CrossRef]

9. Tian, G.C.; Li, J.; Hua, Y.X. Application of ionic liquids in metallurgy of nonferrous metals. Chin. J. Process Eng. 2009, 9, 200.

10. Tian, G.C.; Li, J.; Hua, Y.X. Application of ionic liquids in hydrometallurgy of nonferrous metals. Trans. Nonferrous Met. Soc. China 2010, 20, 513. [CrossRef]

11. Tian, G.C. Application of Ionic Liquids in Extraction and Separation of Metals in Green Solvent II; Springer: Berlin, Germany, 2012.

12. Tian, G.C. Ionic liquids as green electrolytes for Aluminum and Aluminum-alloy production. Mater. Res. Found. 2019, 54, 249.

13. Zhong, X.W.; Xiong, T.; Lu, J.; Shi, Z.N. Advances of electro-deposition and aluminum refining of aluminum and aluminum alloy in ionic liquid electrolytes system. Nonferrous Met. Sci. Eng. 2014, 5, 44.

14. Zheng, Y.; Wang, Q.; Zheng, Y.J.; Lv, H.C. Advances in research and application of aluminum electrolysis in ionic liquid systems. Chin. J. Process Eng. 2015, 15, 713.

15. Fleury, V.; Kaufman, J.H.; Hibbert, D.B. Mechanism of a morphology transition in ramified electrochemical growth. Nature 1994, 367, 435. [CrossRef]

16. Yue, G.; Lu, X.; Zhu, Y.; Zhang, X.; Zhang, S. Surface morphology, crystal structure and orientation of aluminum coatings electrodeposited on mild steel in ionic liquid. Chem. Eng. J. 2009, 147, 79. [CrossRef]

17. Abbott, A.P.; Qiu, F.; Abood, H.M.; Ali, M.R.; Ryder, K.S. Double layer, diluent and anode effects upon the electrodeposition of aluminum from chloroaluminate based ionic liquids. Phys. Chem. Chem. Phys. 2010, 12, 1862. [CrossRef] [PubMed]

18. Liu, L.; Lu, X.; Cai, Y.; Zheng, Y.; Zhang, S. Influence of additives on the speciation, morphology, and nanocrystallinity of aluminum electrodeposition. Aust. J. Chem. 2012, 65, 1523. [CrossRef]

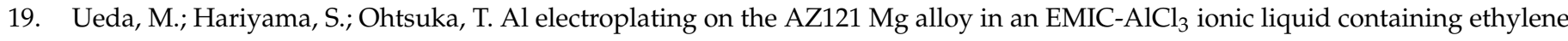
glycol. J. Solid State Electrochem. 2012, 16, 3423. [CrossRef]

20. Zhang, Q.; Wang, Q.; Zhang, S.; Lu, X. Effect of nicotinamide on electrodeposition of $\mathrm{Al}$ from aluminum chloride (AlCl $\left.{ }_{3}\right)-1-$ butyl3-methylimidazolium chloride ([BMIM]Cl) ionic liquids. J. Solid State Electrochem. 2014, 18, 257. [CrossRef]

21. Wang, Q.; Zhang, Q.; Chen, B.; Lu, X.; Zhang, S. Electrodeposition of bright Al coatings from 1-butyl-3-methylimidazolium chloroaluminate ionic liquids with specific additives. J. Electrochem. Soc. 2015, 162, D320. [CrossRef]

22. Wang, Q.; Chen, B.; Zhang, Q.; Lu, X.; Zhang, S. Aluminum deposition from lewis acidic 1-butyl-3-methylimidazolium chloroaluminate ionic liquid ([BMIM]Cl/ $\mathrm{AlCl}_{3}$ ) modified with methyl nicotinate. ChemElectroChem 2015, 2, 1794. [CrossRef] 
23. Sheng, P.F.; Chen, B.; Shao, H.B.; Wang, J.M.; Zhang, J.Q.; Cao, C.N. Electrodeposition and corrosion behavior of nanocrystalline aluminum from a chloroaluminate ionic liquid. Mater. Corros. 2015, 66, 1338. [CrossRef]

24. Leng, M.H. Study on Micro Morphology of Aluminum Electrodeposited by Ionic Liquid; Shenyang Normal University: Shenyang, China, 2015.

25. Li, Z.T.; Tian, G.C. Simulation study of the effect of benzene on the structure and properties of 1-ethyl-3-methylimidazolium chloroaluminate. Comput. Appl. Chem. 2015, 32, 1044.

26. Lang, H.; Zhang, J.; Kang, Y.; Chen, S.; Zhang, S. Effects of lithium bis (oxalato) borate on electrochemical stability of [EMIM][Al2C17] ionic liquid for aluminum electrolysis. Ionics 2017, 23, 959. [CrossRef]

27. Endres, F.; Bukowski, M.; Hempelmann, R.; Natter, H. Electrodeposition of nanocrystalline metals and alloys from ionic liquids. Angew. Chem. 2003, 42, 3428-3430. [CrossRef]

28. Liu, Q.X.; Abedin, S.Z.E.; Endres, F. Electroplating of mild steel by aluminium in a first generation ionic liquid, A green alternative to commercial Al-plating in organic solvents. Surf. Coat. Technol. 2006, 201, 1352-1356. [CrossRef]

29. Chang, J.K.; Chen, S.Y.; Tsai, W.T.; Deng, M.J.; Sun, I.W. Electrodeposition of aluminum on magnesium alloy in aluminum chloride $\left(\mathrm{AlCl}_{3}\right.$ )-1-ethyl-3-methylimidazolium chloride (EMIC) ionic liquid and its corrosion behavior. Electrochem. Commun. 2007, 9, 1602-1606. [CrossRef]

30. Liao, Q.; Pitner, W.R.; Stewart, G.; Hussey, C.L.; Stafford, G.R. ChemInform Abstract, Electrodeposition of Aluminum from the Aluminum Chloride-1-methyl-3- ethylimidazolium Chloride Room Temperature Molten Salt + Benzene. Cheminform 1997, 144, 936-943. [CrossRef]

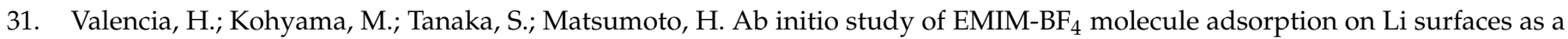
model for ionic liquid/Li interfaces in Li-ion batteries. Phys. Rev. B 2008, 78, 205402. [CrossRef]

32. Valencia, H.; Kohyama, M.; Tanaka, S.; Matsumoto, H. Ab initio study of EMIM-BF 4 crystal interaction with a Li (100) surface as a model for ionic liquid/Li interfaces in Li-ion batteries. J. Chem. Phys. 2009, 131, 244705. [CrossRef]

33. Clarke-Hannaford, J.; Breedon, M.; Best, A.S.; Spencer, M.J. The interaction of ethylammoniumtetrafluoroborate $\left[\mathrm{EtNH}_{3}{ }^{+}\right]\left[\mathrm{BF}_{4}{ }^{-}\right]$ ionic liquid on the $\mathrm{Li}$ (001) surface, towards understanding early SEI formation on Li metal. Phys. Chem. Chem. Phys. 2019, 21, 10028-10037. [CrossRef]

34. Zhang, Q.Q. Study on Electrodeposition of Aluminum and Aluminum Alloy in Ionic Liquid; University of Chinese Academy of Sciences: Beijing, China, 2014.

35. Frisch, M.J.E.A.; Trucks, G.W.; Schlegel, H.B.; Scuseria, G.E.; Robb, M.A.; Cheeseman, J.R.; Scalmani, G.; Barone, V.; Mennucci, B.; Petersson, G.; et al. Gaussian 09 Revision A, 3rd ed.; Gaussian, Inc.: Wallingford, UK, 2009.

36. Lu T, Chen F Multiwfn: A multifunctional wavefunction analyzer. J. Comput. Chem. 2012, 33, 580-592. [CrossRef]

37. Kresse, G.; Furthmüller, J. Efficiency of ab-initio total energy calculations for metals and semiconductors using a plane- wave basis set. Comput. Mater. Sci. 1996, 6, 15-50. [CrossRef]

38. Kresse, G.; Hafner, J. Ab initio molecular dynamics for liquid metals. Phys. Rev. B 1993, 47, 558-561. [CrossRef]

39. Perdew, J.P.; Burke, K.; Ernzerhof, M. Generalized gradient approximation made simple. Phys. Rev. Lett. 1996, 77, 3865-3868. [CrossRef]

40. Grimme, S.; Ehrlich, S.; Goerigk, L. Effect of the damping function in dispersion corrected density functional theory. J. Comput. Chem. 2011, 32, 1456-1503. [CrossRef] [PubMed]

41. Kolsbjerg, E.L.; Groves, M.N.; Hammer, B. Pyridine adsorption and diffusion on the Pt (111) investigated with density functional theory. J. Chem. Phys. 2016, 144, 164112. [CrossRef] [PubMed]

42. Saeys, M.; Reyniers, M.; Marin, G.B.; Neurock, M. Density Functional Study of Benzene Adsorption on the Pt (111). J. Phys. Chem. B 2002, 106, 7489-7498. [CrossRef]

43. Kokalj, A.; Peljhan, S.; Finsgar, M. What determines the inhibition effectiveness of ATA, BTAH, and BTAOH corrosion inhibitors on copper. J. Am. Chem. Soc. 2010, 132, 16657-16668. [CrossRef] [PubMed]

44. Delley, B. Hardness conserving semilocal pseudo potentials. Phys. Rev. B 2002, 66, 155-165. [CrossRef] 